УДК 007

\title{
СТРУКТУРА ИНФОРМАЦИОННЫХ ПОТОКОВ ОРГАНОВ МУНИЦИПАЛЬНОГО УПРАВЛЕНИЯ
}

\author{
Данилина Елена Ивановна \\ доктор экономических наук, профессор \\ Институт деловой карьеры
}

\begin{abstract}
Аннотация: В статье показана структура и свойства информационных потоков, особенности и приоритеты задач, решаемых подразделениями организации, указаны критерии проектирования информационных потоков. Представлены результаты анализа взаимосвязи между органом управления и СМИ, органами государственной власти. По результатам исследования обоснован алгоритм решения принципиальных вопросов проектирования информационной системы регионального и муниципального управления.

Ключевые слова: информация, информационные потоки, критерии проектирования информационных потоков, модели публичного управления, органы управления, органы государственной власти.
\end{abstract}

\section{STRUCTURE OF INFORMATION FLOWS OF MUNICIPAL GOVERNMENT BODIES}

\section{Danilina Elena Ivanovna}

\begin{abstract}
The article shows the structure and properties of information flows, the features and priorities of the tasks solved by the divisions of the organization, the criteria for designing information flows are indicated. The results of the analysis of the relationship between the governing body and the media, public authorities are presented. Based on the results of the study, an algorithm for solving fundamental issues of designing an information system of regional and municipal management is substantiated.
\end{abstract}

Keywords: information, information flows, criteria for designing information flows, models of public administration, management bodies, public authorities. 
Структура информационных потоков, как отмечает Е.Е. Степанова, определяет их однородность и неоднородность [9]. Однородные информационные потоки характеризуются единым видом носителя, единой функциональной принадлежностью, единым видом документационного сопровождения. Неоднородные информационные потоки соответственно не отвечают всем вышеперечисленным требованиям.

По периодичности информационные потоки делятся на регулярные, соответствующие регламентированной во времени передаче данных, и оперативные - обеспечивающие связь в любой необходимый момент времени.

По степени взаимосвязи информационные потоки делятся на взаимосвязанные и невзаимосвязанные. Степень взаимосвязи характеризуется количеством видов информации, взаимосвязанных с данным видом информации.

По объему информационные потоки делятся на малообъемные, среднеобъемные и высокообъемные. Объем информации измеряется количеством символов (алфавитных, цифровых и служебных знаков) или байтов [5].

Рассматривая структуру информационных потоков органов муниципального управления, В.А. Никитов, прежде всего, выделяет две большие группы информационных потоков, а именно внешние и внутренние информационные потоки [4]. Внутренние информационные потоки циркулируют внутри системы управления, внешние - связывают систему управления с внешней средой. Внешняя среда, окружающие условия - это необходимый фон, на котором и при опосредованном участии которого развертывается функционирование системы. В связи с этим следует отметить, что в целях повышения эффективности муниципального управления представляется весьма важным изучение в структуре информационных потоков органов местного самоуправления не только внутренних, но и внешних информационных потоков. Важным элементом внешних потоков информации являются результаты социологических опросов - они представляют интерес как для самого предприятия (ведомства, организации), так и для заинтересованных в ее деятельности сторонних организаций и физических лиц. В целях создания благоприятного имиджа крупные организации специально создают отделы по связям с общественностью, пресс-бюро, службы пиар («паблик-рилейшнз») и 
т.д., предназначенные для формирования и распространения в обществе выгодной для организации информации о ней.

А.Н. Райков отмечает, что структура информационных потоков города строится с учетом структуры и процессов функционирования его органов управления, потребностей в информационном обеспечении населения и различных организаций [7]. Распределение по функциональным подсистемам определяет основу структуры информационных потоков городского управления, так как информация в них легко структурируется по предметному признаку, обеспечивая необходимую унификацию для автоматизации процессов сбора, обработки, хранения, накопления в банках данных и использования информации в пределах подсистемы. В интересах совместно решаемых задач между подсистемами осуществляется автоматизированный обмен информацией, что обеспечивает функционирование системы в целом [7].

При всем многообразии информационных потоков в управлении деятельностью организации, по направленности движения информации, А.А. Козырев выделяет горизонтальные и вертикальные [3].

Вертикальные потоки связывают разные уровни управления. Вертикальный поток может быть нисходящим или восходящим. Нисходящий поток (иначе говоря, поток прямой связи) направлен от нижестоящих к вышестоящим субъектам (органам) управления. Восходящий поток имеет обратное направление - от нижестоящих к вышестоящим субъектам (иными словами, поток обратной связи).

Информация вертикального потока, поступающая по каналам прямой связи от субъекта к объекту управления это, главным образом, управляющая или командная информация (приказы, указания, распоряжения и т.п.). Сюда относятся, в частности, новая стратегическая информация, сведения об изменении приоритетов в деятельности организации и ее подразделений, конкретные плановые задания, выписки из плана работ вышестоящей организации, правила, инструкции, стандарты.

Информация, циркулирующая по вертикальному каналу обратной связи, это, в основном, информация осведомления или отчетная информация (доклады подчиненных организаций, подразделений, филиалов или работников о выполнении ранее поступавших указаний, распоряжений, рекомендаций, разного рода статистические и иные отчетные данные, сообщения об изменениях деловой обстановки, сведения о возникающих 
проблемах и т.п.). В этом же потоке может осуществляться и обратное управленческое воздействие. Будучи необязательно реакцией на то или иное управляющее воздействие, оно может возникать независимо от него, по инициативе объекта управления и имеет характер управляющего воздействия (например, заявление о предоставлении очередного отпуска и т.п.). При этом субъект и объект управления как бы меняются местами.

Горизонтальные потоки связывают звенья управления одного уровня (равноправные), обеспечивая координацию их деятельности. Горизонтальные потоки являются следствием информационных, технологических и иных взаимосвязей между различными подразделениями организации, находящимися на одном уровне управления. Указанные потоки обеспечивают координацию их деятельности и взаимодействие. Так, информация, возникающая в процессе согласования с производственными участками генерируемых разрабатывающим подразделением предприятия изменений (инноваций, усовершенствований) технологического производственного процесса на предприятии, является элементом именно горизонтального потока информации [2].

Другим основанием для классификации информационных потоков являются наличие ограничений на распространение составляющих эти потоки информации. По этому основанию Э.П. Голенищев выделяет открытые (гласные, официальные) и закрытые (оперативные, негласные) информационные потоки [1]. Открытые потоки составляет информация, на распространение которой ограничений не установлено. Закрытые потоки образуют сведения конфиденциального характера, на распространение которых в определенном законом порядке установлены ограничения. Для государственных учреждений, предприятий, организаций, это может быть служебная информация, а также информация, составляющая государственную или военную тайну. Для общественных и частных организаций такого рода потоки образует, прежде всего, информация, составляющая коммерческую тайну, а также профессиональную тайну. Для закрытых потоков, как правило, создается отдельная система регистрации, ознакомления и работы с информацией (прежде всего, ее хранения и использования). Внутренние и внешние информационные потоки могут включать в себя как закрытую (секретную или конфиденциальную), так и открытую информацию. 
По признаку использования при передаче информации сложившихся организационных структур различают формальные и неформальные информационные потоки. Движение формальных потоков фиксируется с помощью различного рода носителей информации - печатных или электронных. Значительную часть этих потоков составляет документированная информация. Подобного рода потоки являются отражением использования субъектом управления, прежде всего, административных методов управления $[2]$.

Необходимо иметь в виду, что в любой организации, помимо формальных потоков, опирающихся на существующую организационную структуру, существуют (иногда приобретают большое значение) неформальные потоки. Неформальные потоки опираются на имеющиеся неформальные связи между работниками организациями (необязательно одного уровня управления), отражают их взаимные симпатии и информационные предпочтения. Указанные потоки возникают, в частности, в результате стремления работников обойти установленные ограничения на распространение служебной (закрытой) информации. Наиболее важны такого рода потоки в спонтанно формирующихся неформальных коллективах. Указанные неформальные потоки образуют, главным образом, устные сообщения, хотя нельзя исключать и отдельные фрагменты формальных потоков в документальной форме или в электронном виде. Подобного рода потоки могут быть отражением использования субъектом управления, прежде всего, информационных и психологических методов управления.

При проектировании информационных потоков в числе важнейших обычно выделяют следующие критерии: оперативность ознакомления субъектов управления и специалистов организации с вновь поступающей и генерируемой в самой организации информацией; информированность субъектов управления и специалистов организации в объеме, необходимом для выполнения ими своих функций (служебных обязанностей); минимизация трудозатрат, связанных с формированием, передачей информации и ознакомлением с ней субъектов управления и специалистов организации; защищенность конфиденциальной информации организации от несанкционированного доступа к ней.

Важное значение имеет приоритетность задач, решаемых подразделениями организации, ориентированность их деятельности вовне или направленность ее 
внутрь самой организации, требования к уровню оперативности принимаемых ими решений (а они различны, например, для производственного и научного подразделений). Учитывается также характер и интенсивность информационных взаимосвязей подразделений организации.

Запаздывание в ознакомлении субъектов управления и специалистов организации с вновь поступающей и генерируемой в самой организации информацией уменьшает ценность циркулирующей в организации информации по критерию своевременности. Следствием этого является увеличение дефицита времени для их разработки, задержки в принятии решений и их доведении до исполнителей, принятие решений с опозданием («бить по хвостам») и потери иногда драгоценного времени для их реализации. С другой стороны, недостаточная оперативность в информировании приводит к усилению действия эффекта неопределенности при принятии управленческих решений, к необходимости принимать управленческие решения в условиях ограниченности времени. Для субъекта управления это выступает в качестве дополнительного мощного стрессогенного фактора, что в результате существенно снижению эффективности принимаемых управленческих решений в организации [6].

Недостаточная информированность субъектов управления и специалистов организации имеет своим следствием приложение ими неоправданных усилий по организации и проведению самостоятельных разработок по проблемам, уже исследованным и доведенным до практической реализации (попытки «изобрести велосипед») и приводит, как правило, к нарастанию отставания организации в области инноваций. Особое значение это имеет для научнотехнических фирм.

Завышенные трудозатраты, связанные с формированием, передачей информации и ознакомлением с ней субъектов управления и специалистов организации, носят постоянный характер, означают неэффективное использование имеющего кадрового потенциала организации, снижают ее целевую эффективность и наносят ущерб финансовому состоянию.

Искажение и разрушение информации может иметь своим следствием материальный и моральный ущерб для организации. В частности, искажение научно-технической информации может привести к затягиванию сроков исполнения работ и даже к снижению качества научно-технических разработок. 
Информацию в структурных подразделениях органа муниципального управления, по мнению В.А. Никитова, можно классифицировать по следующим основным признакам:

- функциональному назначению и характеру деятельности структурных подразделений;

-отношению сообщения к субъекту, управляющему структурным подразделением;

- типу связи структурного подразделения и внешней среды. Выделяется информация, циркулирующая в прямой и обратной связи между отделами органа управления, отделами и самим органом управления, между отделами и внешней средой. Анализируются взаимосвязи между органом управления и СМИ, органами государственной власти и т.д.;

- отношению к целевой функции структурного подразделения. Из всего объема пришедшей в подразделение информации необходимо выделить ту, которая наиболее полно соответствует его целям и задачам;

- логическому содержанию. Информация структурного подразделения может подразделяться на три самостоятельных подмножества: о субъектах органа управления, объектах его управленческого воздействия (муниципальных предприятиях, организациях, гражданах и т.д.) и присущих им свойствах и отношениях;

- физической форме представления (устный доклад, сообщение на бумаге в виде текстов, анкет и т.д., поступления по электронной почте, факсу, из информационных систем, на дискетах и т.д.);

- процедуре преобразования (вероятностные, социологические, моделирующие, вычислительные и т.д.);

- степени преобразования (основная или вновь поступающая, обработанная в аналитические и прогнозные записки, сгруппированная в информационные еженедельники и бюллетени и т.д.) [4].

Информация и ее потоки в муниципальном управлении могут разбиваться также в зависимости от источников (население, муниципальные предприятия и организации, вышестоящие государственные органы и т.д.), качественного содержания (вычисление ценной по содержанию информации, от которой зависят управленческие воздействия, исходящие от структурных подразделений), количественных характеристик (целесообразно выделить вероятностные, семантические и иные меры информации, используемые при 
управленческом регулировании и обеспечении других управленческих потребностей).

М.А. Сергеев перечисляет виды, источники и получателей информации, поступающей в администрацию города:

От населения - поступает в первичные отделы районных администраций и администрации города: письма, жалобы, заявления, обращения.

От организаций и предприятий - поступает в профильные отделы районных администраций, откуда затем после обработки отправляется в соответствующий профильный департамент администрации города:

-социальная - информация о различных слоях населения (военнослужащих, пенсионерах, несовершеннолетних);

-экономическая - информация о ценах, налогах, финансовоэкономическом положении предприятий, статистическая;

-юридическая, правовая - законы, указы, постановления, распоряжения, письма и циркуляры;

- организационная - письма, обращения и т.д.;

- справочная - реестры, справочники, перечни [8].

Таким образом, в целом классификация позволяет получать ценные сведения об информации, содержащейся в структурных подразделениях аппарата управления, способствует решению многих принципиальных вопросов проектирования информационной системы регионального и муниципального управления и анализа соответствующего обеспечения структурных подразделений.

\section{Список литературы}

1. Голенищев Э.П., Клименко И.В. Информационное обеспечение систем управления. Ростов н/Д, 2016. - 325 с.

2. Зайцев Д.Р. Применение информационных технологий и систем для повышения эффективности управления организацией / Д.3. Зайцев // Территория науки, 2015. № 2. С. 96-103.

3. Козырев А.А., Информационные технологии в экономике и управлении: учебник, М. - 2015. - 358 с.

4. Никитов В.А. Информационное обеспечение муниципального управления. М.: КноРус. - 2017. - 266 с. 
5. Могилевский В.Д. Методология систем: вербальный подход. М.: АО «Издательство «Экономика», 2015. - 258 с.

6. Плотников М. В. Эффективные коммуникации в организации. [Электронный ресурc] - URL: http://www.elitarium.ru

7. Райков А.Н. Информационно-аналитические технологии для федеральных органов исполнительной власти [Электронный ресурс] http://www.regionstudy.narod.ru

8. Сергеев М.А Информатизация начинается с местного самоуправления //Электронный ресурс: www.politcom.ru

9. Степанова Е.Е, Хмелевская Н.В. Информационное обеспечение управленческой деятельности. М. - 2016. - 358 с.

() Е.И. Данилина, 2021 